\title{
Intragastric Balloon (BIB) for the Management of Obesity, Report on the First Egyptian Experience
}

\author{
Hossam Ghoneim ${ }^{1}$, Iman Hamza ${ }^{2 *}$ \\ ${ }^{1}$ Endemic Medicine, Beni-Sweif University, Cairo, Egypt \\ ${ }^{2}$ Endemic Medicine, Cairo University, Cairo, Egypt \\ Email: *iman hamza@hotmail.com
}

Received 19 June 2014; revised 5 August 2014; accepted 20 August 2014

Copyright (C) 2014 by authors and Scientific Research Publishing Inc.

This work is licensed under the Creative Commons Attribution International License (CC BY). http://creativecommons.org/licenses/by/4.0/

(c) (i) Open Access

\begin{abstract}
Introduction: The bioenteric balloon (BIB) is widely applied in the management of obesity. Aim of the work: This is a report on the efficacy and safety of $B I B^{\circledR}$ device in the first 101 Egyptian cases. Methods: Patients referred for BIB between January 2011 till December 2012 were evaluated retrospectively. BIB was inserted for 6 months according to predetermined inclusion and exclusion criteria. Results: In 101 cases, 17 cases were males $(16.8 \%)$ and 84 cases were females $(83.2 \%)$, mean age $33.2( \pm 10.44)$ years, mean BMI $35.9( \pm 4.65) \mathrm{kg} / \mathrm{m}^{2}$. None of the patients exhibited balloon migration or perforation. The balloon was removed upon request in 3 patients due to exaggerated intolerance $(2.9 \%)$. The mean weight loss was $15.5 \mathrm{~kg}( \pm 4.67)$, mean EWL $64.12 \%$ $( \pm 23.48 \%)$. The mean BMI at extraction was $29.7 \mathrm{~kg} / \mathrm{m}^{2}( \pm 4.48)$ with a BMI loss of $6.2 \mathrm{~kg} / \mathrm{m}^{2}( \pm 2.0)$. 87 patients (88.7\%) achieved target EWL (32.1\% of excess weight), and 87 patients lost $>12.2 \%$ of their basal weight (88.7\%). 70 patients achieved BMI loss $>5.7 \mathrm{~kg} / \mathrm{m}^{2}(71.4 \%)$. Conclusion: BIB achieves acceptable success with minimal complications. In further long term, prospective studies are needed to evaluate obesity related comorbidities when using such modality and to compare it to other available devices.
\end{abstract}

Keywords

Bioenteric Balloon, Obesity, Weight Loss

\section{Introduction}

Between 1980 and 2004 the prevalence of obesity increased from 15\% to 33\% among adults and the prevalence

${ }^{*}$ Corresponding author.

How to cite this paper: Ghoneim, H. and Hamza, I. (2014) Intragastric Balloon (BIB) for the Management of Obesity, Report on the First Egyptian Experience. Open Journal of Gastroenterology, 4, 295-304.

http://dx.doi.org/10.4236/ojgas.2014.48043 
of overweight in children increased from more than $6 \%$ to $19 \%$ in the United States. Once considered a high-income country problem, overweight and obesity are now on the rise in low- and middle-income countries, particularly in urban settings [1].

The real burden of obesity as a social health problem is its association with an increased risk of numerous chronic diseases, type II diabetes, coronary heart disease, cerebrovascular stroke and even malignancy. Consequently, the obesity epidemic exerts a heavy toll on the economy with its massive healthcare costs. The problem of overweight and obesity has therefore emerged as one of the most pressing global issues for the coming several decades, and demands attention from the healthcare community, researchers, and policy makers [2] [3].

Broadly, management of obesity comprises primary management of obesity, management of obesity-related diseases and management of complications of bariatric surgery like bleeding, anastomotic strictures and fistulae [4]. The spectrum for endoscopic management of obesity is wide. It comprises gastric volume reduction procedures by balloon insertion, stapling or plication devices as well as small bowel approach procedures like the duodenal-jejunal bypass sleeve [5].

The very first reports on the use of intragastric balloon devices date back to the early 80s and continue to evolve till present. The cylindrical air-filled Garen Edward bubble balloon was the first introduced. Its low efficacy, rapid deflation and sometimes possible migration led to its discontinuation. In 1987, the Tarpon Spring conference recommended that a suitable intragastric device had to be fluid filled, adjustable to various sizes, and had a smooth durable and non-ulcerogenic surface. It should also contain a radio-opaque marker to be seen on X-ray in follow-up and should be made of durable materials that do not leak [6]. The most known intragastric balloon for treatment of obesity is the BIB (balloon of BioEnterics, Inamed Corporation, Arklow, County Wicklow, Ireland and Bioenterics Corporation, carpentry, California, USA). It was first introduced in 1999, and complied with the above mentioned criteria. After its insertion, BIB exerts a restrictive effect causing a sense of fullness, decreasing gastric emptying and thus producing early satiety. Additionally, it may be believed to cause decrease in plasma levels of ghrelin [7] [8].

BIB insertion is an easy ambulatory out-patient procedure done under sedation. Its inflated diameter reaches about $13 \mathrm{~cm}$ which can be tailored to the patients' condition. It is filled with an average of 500 ccs saline colored with 10 ccs methylene blue, serving as a marker of early leak from the balloon (being excreted in urine). In 2001 Evans and Scott reported an 18.7\% EWL (excess weight loss) among 63 studied cases with a mean BMI (body mass index) of $46.3 \mathrm{~kg} / \mathrm{m}^{2}$. The BIB migration rate in their series was $4.7 \%$. In a larger scale study on 2515 cases with a mean BMI of $44.4 \mathrm{~kg} / \mathrm{m}^{2}$ Genco and co-workers reported an EWL of $33.9 \%$ [9].

Although BIB is considered safe, some complications have been reported. The most common of these is the early intolerance occurring in the first few days following insertion and may rarely extend up to few weeks necessitating patient hospitalization to ensure hydration and blood chemistry homeostasis. Intolerance seen as abdominal pain, nausea and vomiting are usually variable from one patient to another. Rare complications that have been reported include gastric bleeding, ulcerations and regurge without necessitating premature balloon removal $1 \%-2.5 \%$ [7] [9]-[11].

Aim of the work: The aim of the current study is to assess the efficacy and safety and tolerance of BIB ${ }^{\circledR}$ device in terms of weight reduction and management of obesity.

\section{Patients and Methods}

Patients who were referred for balloon insertion during the period between January 2011 and December 2012 were evaluated retrospectively. Before the procedure, patients were subjected to clinical assessment, weight, height, and BMI calculation. The procedure was done after both written and informed consents were obtained. Patients were well informed about the procedure, its potential success and potential complications.

All patients were given a dieting and medical treatment regimen program for the post procedural period extending for one month, and they were referred to a specialized nutritionist to carry out a specified nutritional and behavioral educational program for the six months to follow the procedure until extraction of the device.

Patient enrollment was according to pre-determined inclusion and exclusion criteria. The inclusion criteria were patients aged 18 years or older who failed to achieve adequate weight loss within a supervised weight-control program, BMI more than or equal to $30 \mathrm{~kg} / \mathrm{m}^{2}$. The exclusion criteria were considered in case of hormonal or genetic causes for obesity, neoplastic disease, pregnancy or a desire to become pregnant within the following six months, large hiatus hernia, gastro esophageal reflux disease (GERD) (LA grade C-D), peptic ulceration, esophageal or gastric varices, angioectasias and previous bariatric or abdominal surgery. Patients who were high 
risk for sedation and those whose general health would preclude surgery should a complication occur were excluded as well. Patients under treatment with anti-coagulation were also excluded.

\subsection{The Balloon}

The Bioenteric Intra-gastric Balloon (BIB), is small and flexible in the collapsed state, it expands into a spherical shape $10 \mathrm{~cm}$ in diameter when filled with $500 \mathrm{ml}$ saline solution. Its shell is made of an inert, nontoxic silicon elastomer that is resistant to gastric acid. The balloon has a radiopaque self-sealing valve that allows adjustment of the volume in a range of 400 to $700 \mathrm{ml}$.

\subsection{The Technique as Provided by the Manufacturer Instructions}

1) A-Implantation

After intravenous administration of (Propofol $2 \mathrm{mg} / \mathrm{kg}$ ) endoscopy is performed to rule out abnormalities that would preclude implantation. The balloon device consists of a sheath of the deflated balloon attached to a tube with a stiffening wire. The device is introduced down the esophagus gently till the $40 \mathrm{~cm}$ mark on the tube is reached. The endoscope is then passed to the stomach side by side with the placement assembly tube to aid further introduction of the balloon under direct vision to the stomach (just before the antrum).

The stiffening wire is then withdrawn and the balloon is inflated with the scope in retroflexion position. The inflating fluid is injected through a one-way valve allowing suction of the inflating material from the container and re-injecting it into the balloon. Procedure is done under direct vision.

The used volume was a standard of $550 \mathrm{ml}$ saline solution mixed with $10 \mathrm{ml}$ Methylene blue. The latter served as a color indicator in case of leakage, where any leakage can be noticed through urine excretion being bluish or greenish in color.

To release the balloon, gentle suction is exerted on the assembly tube by withdrawing the plunger of the syringe, this creates negative pressure that seals the self-adhesive valve in the balloon, then the balloon is released by a short pull on the fill tube setting the balloon free in the gastric body without any antral impaction (Figure 1) [12]-[14].

2) Post procedure care

To guard or to manage any patient discomfort or nausea in the first few hours after the procedure the following was given: I.V. proton pump inhibitor infusion, I.V. anti-spasmodic (e.g. Butylscopolamine (buscopan)), I.V. antiemetic (Metochlopramide, Ondansteron (Zofran)), I.V. paracetamol, in addition to 2500 - 3000 cc of IV fluid for the first 24 hours post procedure observation time in hospital.

The following day on discharge, the patients were given antiemetic suppositories for 3 days, sapsmolytic suppositories for 3 days, analgesics (not Non steroidal anti-inflammatory drugs) per needed, proton pump inhibitor 40mg daily for two weeks.

After discharge, patients were advised to follow up liquid diet gradually transient to solid diet to allow the stomach to adapt to the presence of the foreign body over a period of two weeks, after which they can start eating normal diet. Patients were referred to their dietician to maintain the suitable calculated daily caloric diet de-

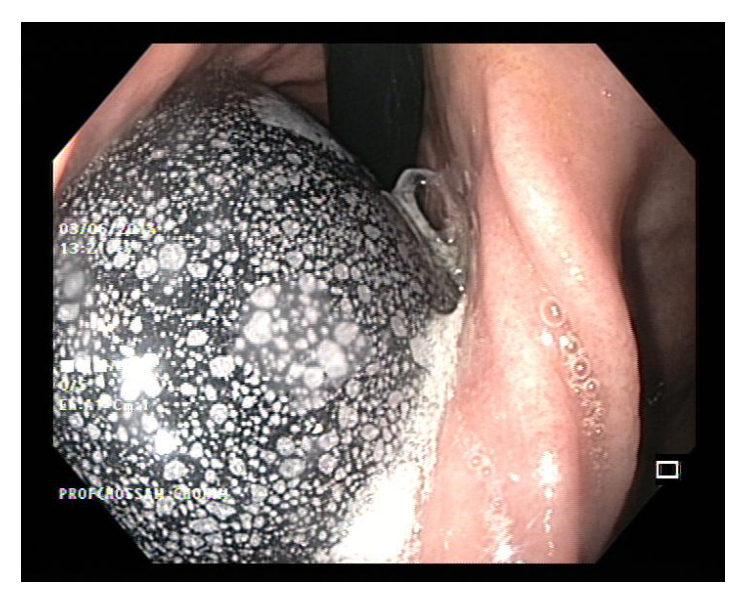

Figure 1. Inflated balloon in retroflexion. 
void of any weight lowering medications.

Patients were revised every week for the first month then monthly for the remaining five months. This involved weight record, offering psychological support, recording and managing complications. In case of intolerance (persistent severe nausea or vomiting, with intractable epigastric pain) patient were hospitalized, abdominal imaging (ultrasonography and/or plain X-ray) was performed to check balloon position, and IV fluids administered to nourish, correct electrolyte deficits if present and add antiemetic and spasmolytic drugs.

3) B-Extraction

The patient is instructed to be on clear liquid diet for 24 hours and prolonged fasting for 12 hours before extraction procedure to avoid presence of food and chime during the procedure.

Special extraction kit is provided by the manufacturer, it is composed of a long puncture sharp needle attached to a wide sheath with few markings on the distal end which when inserted deep enough in the balloon after puncturing it, denote that the tip of the sheath is well inserted in the bottom of the balloon and the extraction forceps (balloon grasper) which has specially designed hooks to ensure a good grip on the balloon all the way through its extraction reducing the risk of slipping specially at the upper or lower esophageal sphincters.

At the allocated time, endoscopy is performed after intravenous administration of propofol $2 \mathrm{mg} / \mathrm{kg}$. The extraction kit-needle is inserted through the working channel of the endoscope. The needle is then advanced to puncture the balloon deep the whole length of the sheath markings, this means that the sheath has gained adequate depth in the balloon cavity (Figure 2). The needle is then withdrawn and suction of the whole volume used in inflation is performed till the balloon is fully collapsed (Figure 3).

The bipolar hook grasp is then used to extract the balloon firmly. Preferably vertically than horizontally and that 2 or more balloon folds are grasped so that a safer extraction is attained (Figure 4, Figure 5). After extrac-

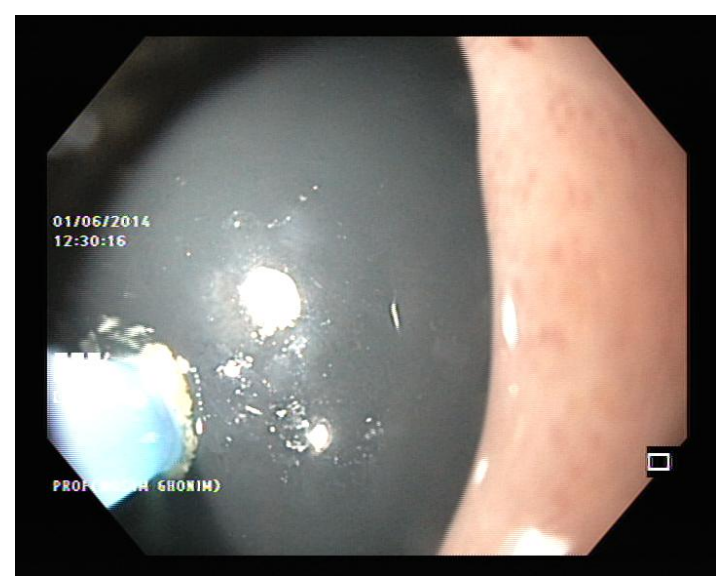

Figure 2. Balloon killer needle puncturing the balloon at extraction.

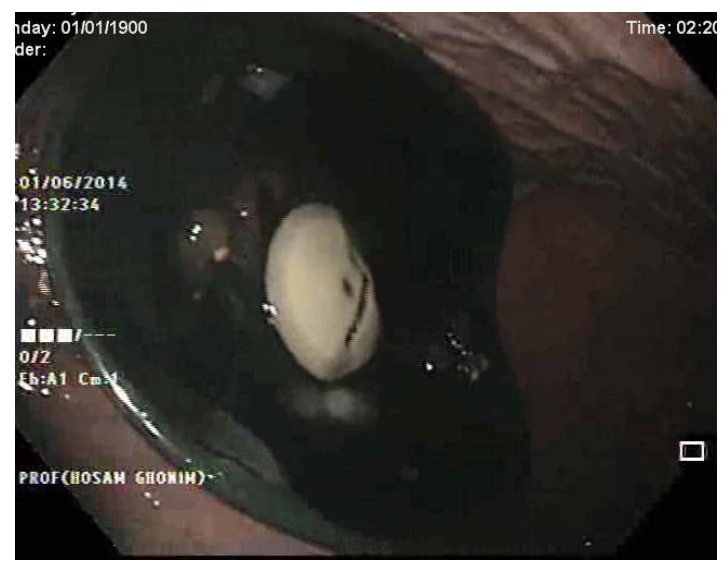

Figure 3. Fully deflated balloon before extraction. 


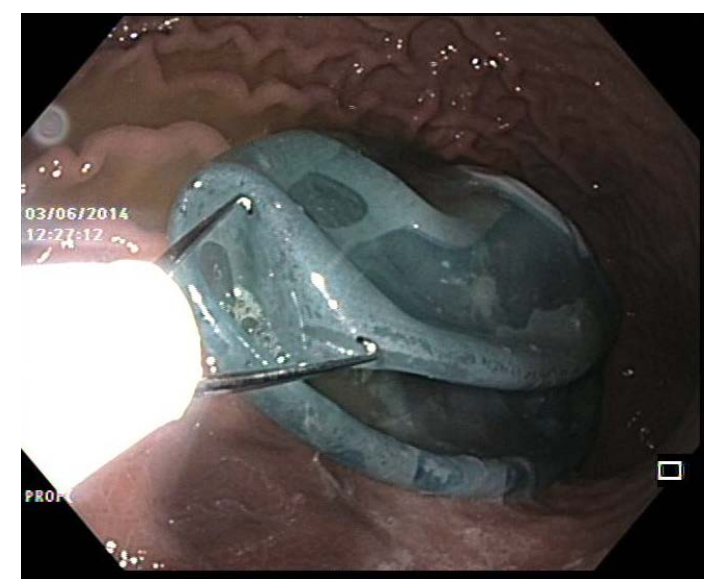

Figure 4. Balloon grasper.

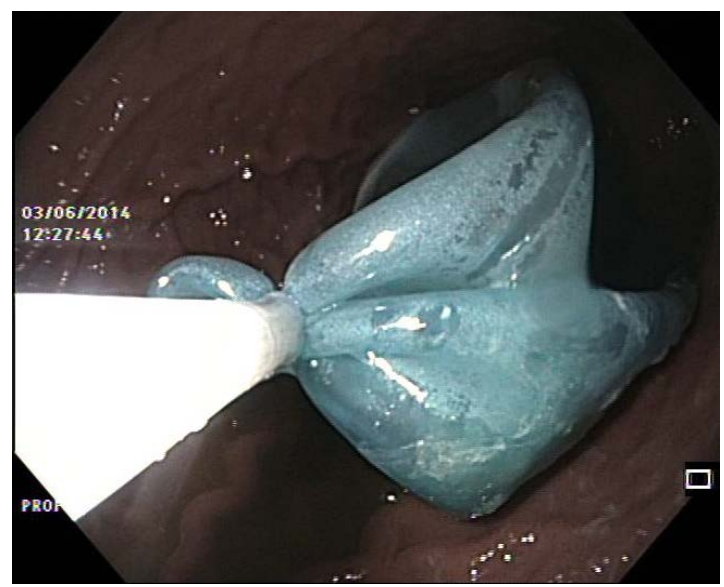

Figure 5. Deflated balloon grasped at extraction.

tion, a second look endoscopy is performed to evaluate for any mucosal abnormalities. Patients are discharged on the same day of extraction.

Following extraction, patients were evaluated in terms of body weight, BMI, actual lost weight, and excess weight loss\% (EWL\%). The latter is calculated as the percent of the actual lost weight in relation to the ideal lost weight. Ideal lost weight is the weight loss needed so that the BMI is kept less than $25 \mathrm{~kg} / \mathrm{m}^{2}$ and more than 18.5 $\mathrm{kg} / \mathrm{m}^{2}$. A loss of $14.7 \mathrm{~kg}$ from initial weight, $5.7 \mathrm{~kg} / \mathrm{m}^{2}$ from basal BMI, and $32.1 \%$ of excess weight were considered estimates of adequate weight loss [12].

Statistical Analysis: Patients' data were tabulated and processed using Statistical Package of Social Sciences (SPSS) (10.0) statistical package. Quantitative variables were expressed by means and standard deviation. While qualitative data were expressed by frequency and percent. Qualitative variables were analyzed using Chi-square or Ficher's exact test when appropriate. Quantitative variables were analyzed using student's T-test or Friedmann's test when appropriate. In all tests $\mathrm{P}$ value was significant when $<0.05$.

\section{Results}

During the study period 117 patients were referred for balloon insertion, only 101 fitted the inclusion criteria (86\%), and 16 patients were excluded (14\%) due to: past history of gastric surgery (1 patient, $0.85 \%)$, presence of large hiatal hernia on index endoscopy (4 patients, 3.4\%), presence of moderate to severe gastritis (7 patients $5.9 \%$ ), presence of duodenal ulcer (4 patients, $3.4 \%$ ).

Out of the 101 cases enrolled in the study, 17 cases were males (16.8\%) and 84 cases were females (83.2\%). With male:female ratio of approximately 1:5. Their mean age was $33.2( \pm 10.44)$ years. Hypertension was re- 
ported in 26 cases (25.7\%), Diabetes Mellitus in 30 cases (29.7\%), and none of the patients had ischemic heart disease. The basal measurements for the included patients are shown in Table 1, while in Table 2 comparison of males and females characteristics are shown.

Following balloon insertion, almost all patients developed variable grades of abdominal pain and vomiting during the first week post procedure. Re-hospitalization for symptoms of intolerance seen as abdominal pain and vomiting were reported in 30 cases (29.7\%). None of these patients exhibited balloon migration or had perforation. However, the balloon was removed upon request in 3 patients due to exaggerated intolerance (2.9\%).

There were no procedure related mortalities, No balloon leakage, or perforations. At extraction, small gastric erosions were reported in 2 patients (1.98\%) while one patient developed grade A reflux esophagitis (0.99\%). The over-all complication rate was $5.9 \%$

At the time of balloon extraction the mean weight loss of the studied patients was $15.5 \mathrm{~kg}( \pm 4.67)$, with a mean EWL of $64.12 \%( \pm 23.48 \%)$. The mean BMI at extraction was $29.7 \mathrm{~kg} / \mathrm{m}^{2}( \pm 4.48)$ with a BMI loss of 6.2 $\mathrm{kg} / \mathrm{m}^{2}( \pm 2.0)$. Also, 87 patients $(88.7 \%)$ achieved the target EWL (32.1\% of excess weight), 87 patients lost $>12.2 \%$ of their basal weight $(88.7 \%)$. Based on BMI loss $\left(>5.7 \mathrm{~kg} / \mathrm{m}^{2}\right), 70$ patients achieved this target (71.4\%).

After excluding the early balloon extraction (3 cases), 98 patients fulfilled the study period. They were regrouped into those who achieved target BMI loss (70 patients) and those who failed to achieve target BMI loss (28 patients). Their data are shown in Table 3.

\section{Discussion}

As per the World Health Organization, Egypt ranks the 14th regarding the prevalence of worldwide obesity. The prevalence of obesity among Egyptian school children has increased by more than 2 folds between 1990 (6\%) and 2010 (15\%). There are Earlier reports on successful weight reduction (more than 5\% of basal body weight) in $28 \%$ of overweight and obese Egyptian adolescents using only diet control and physical exercise regimes.

Table 1. Pre-balloon measurements for studied patients.

\begin{tabular}{ccc}
\hline Variables & Mean/Number & SD/\% \\
\hline Weight $(\mathrm{kg})$ & 89.05 & \pm 19.83 \\
Height $(\mathrm{m})$ & 1.56 & \pm 0.117 \\
Excess weight $(\mathrm{kg})$ & 27.5 & \pm 13.3 \\
BMI $\left(\mathrm{kg} / \mathrm{m}^{2}\right)$ & 35.9 & \pm 4.65 \\
BMI ranges & & $52.4 \%$ \\
$30.0-34.9$ & 53 & $22.7 \%$ \\
$35-39.9$ & 23 & $24.7 \%$ \\
$\geq 40$ & 25 &
\end{tabular}

Table 2. Comparison of baseline data in relation to sex distribution.

\begin{tabular}{|c|c|c|c|c|c|}
\hline & \multicolumn{2}{|c|}{ Males (17) } & \multicolumn{2}{|c|}{ Females (84) } & \multirow{2}{*}{$\mathrm{p}$} \\
\hline & Mean/number & $\mathrm{SD} / \%$ & Mean/number & $\mathrm{SD} / \%$ & \\
\hline Age & 32.11 & 8.88 & 33.5 & 10.76 & 0.62 (NS) \\
\hline Weight (kg) & 114.9 & 17.17 & 83.8 & 15.8 & $<0.01(\mathrm{~S})$ \\
\hline Excess weight & 40.7 & 15.2 & 24.8 & 11.2 & $<0.01(\mathrm{~S})$ \\
\hline BMI $\left(\mathrm{kg} / \mathrm{m}^{2}\right)$ & 39.00 & 5.66 & 35.2 & 4.2 & $<0.01(\mathrm{~S})$ \\
\hline \multicolumn{6}{|l|}{ Groups of BMI } \\
\hline $30.0-34.9$ & 4 & 23.5 & 49 & 58.3 & \multirow{3}{*}{$0.01(\mathrm{~S})$} \\
\hline $35-39.9$ & 4 & 23.5 & 18 & 21.4 & \\
\hline$>40$ & 9 & $53 \%$ & 17 & 20.2 & \\
\hline
\end{tabular}


Table 3. Comparison between those who achieved the target BMI loss to those who failed to achieve target BMI loss.

\begin{tabular}{|c|c|c|c|c|c|}
\hline \multirow{2}{*}{ Variables } & \multicolumn{2}{|c|}{ Target BMI achieved (70) } & \multicolumn{2}{|c|}{ Target BMI not achieved (28) } & \multirow{2}{*}{$\mathrm{p}$} \\
\hline & Mean/Number & $\mathrm{SD} / \%$ & Mean/Number & $\mathrm{SD} / \%$ & \\
\hline Males & 10 & 14.2 & 7 & 25 & 0.46 \\
\hline Females & 60 & 85.7 & 21 & 75 & $0.04(\mathrm{~S})$ \\
\hline Age (years) & 33.7 & 10.5 & 31.8 & 10.6 & 0.42 \\
\hline Pre-balloon BMI (kg/m²) & 23.3 & 4.83 & 35.6 & 4.38 & $<0.01$ \\
\hline Pre-balloon weight (kg) & 87.12 & 19.65 & 95.2 & 19.8 & $0.07 *$ \\
\hline \multicolumn{6}{|l|}{ Groups of BMI } \\
\hline $30.0-34.9$ & 54 & 77.1 & 22 & 78.5 & \\
\hline $35-39.9$ & 15 & 21.4 & 6 & 21.4 & 0.82 \\
\hline$>40$ & 1 & 1.4 & 0 & 0 & \\
\hline BMI at extraction $\left(\mathrm{kg} / \mathrm{m}^{2}\right)$ & 29.1 & 4.3 & 31.3 & 4.45 & $0.03(S)$ \\
\hline
\end{tabular}

Restrictive procedures such as laparoscopic sleeve gastrectomy and laparoscopic gastric band are the mostly applied bariatric surgical procedures in Egypt. While, more invasive operations as gastric bypass and bilio-pancreatic diversion are generally reserved as a second-stage intervention [15]-[18].

Generally, endoscopic management of obesity has found its way between diet and physical activity on one hand and surgical intervention on the other hand. Endo-luminal devices have been introduced in an attempt to balance the equation of management of obesity. Such equation comprises the invasiveness and risks of bariatric surgery as well as the sole dependence on patients'compliance and tolerance seen in the diet-physical activity combination[13].

Intra-gastric balloons have evolved as one of the popular endo-luminal devices that reside in the stomach and cause early satiety. After many modifications in the specifications of an ideal intra-gastric balloon, BIB has been successfully developed [19] [20]. This study represents the first report on the Egyptian experience using the intra-gastric balloon $\left(\mathrm{BIB}{ }^{\circledR}\right)$ system. It is a single center retrospective study. Although the first credit of balloon insertion in the country date earlier than 2001, yet these were considered as sporadic pilot cases and a part of the learning curve, so they were not included in this research.

Patients under treatment for obesity have variable individual response rates, depending on compliance, motivation, feeding habits, etiology of obesity (familial, genetic), physical activity and drug therapy. To standardize the circumstances under which BIB was placed, we strictly selected an obese cohort with BMI more than or equal to $30 \mathrm{~kg} / \mathrm{m}^{2}$ and excluded those with genetic cause of obesity. We also included patients who were previously maintained on a full diet control program, without adequate weight reduction, as declared by their referring dietician. Although the balloon inflation volume ranges between $400-650 \mathrm{ml}$ [13], we standardized the fill volume to $550 \mathrm{ml}$. All included patients were referred after balloon insertion to their referring dietician, again, to maintain the suitable calculated daily caloric diet devoid of any weight lowering medications.

Egypt ranks the second among the Arab world in female obesity (48\%) [15]. In our study the majority of studied patients were females (83.2\%) compared to males (16.8\%). Decreased physical activity, sedentary lifestyle and multiple pregnancies may explain this difference. Interestingly, despite the higher prevalence of obesity among females, all the weight and anthropometric measurements in the current study were highly significant among males (Weight, excess weight, BMI and grade of obesity).

Our results concerning the basal BMI were slightly lower than other studies. We reported a mean BMI of 35.9 $( \pm 4.65) \mathrm{kg} / \mathrm{m}^{2}$. Peker et al. $(2010)$ reported a mean BMI of $41.48( \pm 8.28) \mathrm{kg} / \mathrm{m}^{2}$. Dąbrowiecki et al. (2013) reported a mean BMI of $43( \pm 9) \mathrm{kg} / \mathrm{m}^{2}$. Similar to our research, Peker et al. didn’t include patients with BMI less than $30 \mathrm{~kg} / \mathrm{m}^{2}$, on the other hand, Dąbrowiecki et al. provided no information about patient exclusion based on pre-enrollment BMI. The difference in the basal BMI can be attributed to the larger number of patients in our research (101 patients) versus 33 patients in Peker et al. study and only 25 patients in Dąbrowiecki et al. study [19] [21].

Generally, the BIB is considered a safe procedure in this study. Although variable grades of abdominal pain and vomiting were encountered in the first week following insertion, only 30 cases (29.7\%) required re-hosp- 
italization and were kept under observation. They received I.V. fluids, antiemetic and underwent imaging to ensure balloon position. In all of them the balloon was confirmed in place and accordingly they were re-assured. However, in 3 patients (2.9\%) intolerance necessitated balloon removal upon request. The overall reported complications were 5.9\% with no reported cases of perforation or migration. In a meta-analysis by Imaz et al. (2008), data pooled from 13 studies on 3442 patients, they reported early balloon removal in $4.2 \%$ of cases. In $1.8 \%$ of cases, removal was upon request, balloon leakage in $0.2 \%$ and gastric perforation in $0.2 \%$ [12]. In the study by Peker et al. (2010), they reported an overall accepted tolerance of the balloon with no reported mucosal ulcerations, erosions or perforation. Nausea, vomiting and abdominal pain were reported in $19.35 \%$ of cases, yet none of their patients requested balloon removal due to marked intolerance. Interestingly, they reported one case of balloon spontaneous expulsion in stools that, as they stated, was just managed by re-insertion of another balloon [21]. In one case report study, Milone et al. (2014) reported an early acute renal failure within 5 days of balloon insertion, this was attributed to excess vomiting and dehydration, it necessitated urgent balloon removal and renal impairment was managed medically over a 14 day period till the condition was reversed [22].

Heterogeneity in the parameters of success can be seen in the meta-analysis done by Imaz et al. (2008). In 15 selected studies there were 4 different parameters of success including an absolute weight loss of $14.7 \mathrm{~kg}$, a loss of $12.2 \%$ of initial weight, a BMI loss of $5.7 \mathrm{~kg} / \mathrm{m}^{2}$, and or achieving a loss of $32.1 \%$ of excess weight [12]. In our study, the mean absolute weight loss of the studied patients was $15.5 \mathrm{~kg}( \pm 4.67)$, mean EWL was $64.12 \%$ ( $\pm 23.48 \%)$. The mean BMI at extraction was $29.7 \mathrm{~kg} / \mathrm{m}^{2}( \pm 4.48)$ with a BMI loss of $6.2 \mathrm{~kg} / \mathrm{m}^{2}( \pm 2.0)$.

In the study by Peker (2010), they relied on the presence of highly significant difference between the mean BMI before and after 6 months of balloon implantation.The authors didn't individualize the BMI loss for each patient. Similarly, they calculated an overall mean EWL\% $(29.16 \% \pm 15.99 \%)$ without description of how many patients achieved an actual target of EWL\% [21]. In our study more than $70 \%$ of patients achieved individual success parameters: 87 patients (88.7\%) achieved the target EWL (32.1\% of excess weight), 87 patients lost $>12.2 \%$ of their basal weight $(88.7 \%)$. Based on BMI loss $\left(>5.7 \mathrm{~kg} / \mathrm{m}^{2}\right), 70$ patients achieved this target (71.4\%). When patients were sub-grouped according to whether they achieved a target BMI loss or not, they were comparable in terms of the degree of obesity despite a significantly lower BMI in the group achieving the target BMI as compared to the rest.

For a full evaluation of efficacy, follow up of the patients has to be done for invariable periods after balloon extraction. However, it is important to highlight that the longer the follow up period the more the patients population is subject to heterogeneity. For example, in the study by Dastis et al. (2009), with a total study period of 58.1 \pm 19.5 months after intragastric balloon implantation, 3 (3\%) patients were lost due to mortality and 35 cases had undergone bariatric surgery (35\%) and out of 62 patients who completed the follow up period, 13 patients had to undergo balloon re-insertion while 13 patients (13\%) took sibutramine for intermittent course [13]. In another example, but of a homogenous follow up study, is the study by Alfredo et al. (2014). All the studied patients had morbid obesity and all refused to undergo bariatric surgery, despite being good candidates. Accordingly, they were all managed by balloon re-insertion when the patients had regained $\geq 50 \%$ of the weight loss achieved with previous balloon. Surprisingly, a second balloon was a consistent finding in all patients. A 3rd balloon was only seen in $22.2 \%$ of cases. The quality of life test followed up along the study showed better scores in the post treatment period as compared to the base line [23]. From this example, we emphasize that if balloon evaluation is needed in terms of follow up, then this has to be done within a previously planned standardized protocol.

The real impact of any modality of treatment of obesity is the reduction of obesity-related co-morbidities. In a recent research done by Folini et al. (2014). The authors measured the improvement in liver steatosis by chemical-shift magnetic resonance imaging (MRI-LS) and liver enzymes. After 6months of studying 40 obese patients with BMI $42.8 \pm 7.12 \mathrm{~kg} / \mathrm{m}^{2}$, subjects undergoing BIB had significant changes of BMI, weight, liver biochemical profile, HbA1c, insulin, HOMA-IR, fat mass, fat free mass, and MRI-LS. On the other hand, diet-treated obese subjects had no significant change of any parameter under study [24].

\section{Conclusion}

Finally, we conclude that, in the Egyptian experience, after proper patient selection, BIB achieves acceptable success with minimal or insignificant complications. The current study limitations are the lack of long term follow-up prospective design, and also the absent record on the impact of weight loss on obesity related comorbidities. However, since this work represents our initial experience with the procedure, further long term, pros- 
pective studies are recommended so as to evaluate the effect of weight reduction using BIB on the quality of life, and also to compare it to other available procedures whether endoscopic or surgical.

\section{References}

[1] Ogden, L., Carroll, M.D., Curtin, L.R., McDowell, M.A., Tabak, C.J. and Flegal, K.M. (2006) Prevalence of Overweight and Obesity in the United States, 1999-2004. JAMA, 295, 1549-1555. http://dx.doi.org/10.1001/jama.295.13.1549

[2] Moyer, V. (2012) Screening for and Management of Obesity in Adults: U.S. Preventive Services Task Force Recommendation Statement. Annals of Internal Medicine, 157, 373-378.

[3] Kraschnewski, J., Sciamanna, C., Tuckey, H., et al. (2013) A Silent Response to the Obesity Epidemic: Decline in US Physician Weight Counseling. Medical Care, 51, 186-192. http://dx.doi.org/10.1097/MLR.0b013e3182726c33

[4] A-Qadeer, M. (2011) Endoscopic Management of Obesity. Gastroenterology \& Hepatology, 7, 484-486.

[5] Barham, K., Dayyeh, A. and Thompson, C. (2011) Obesity and Bariatrics for the Endoscopist New Techniques. Therapeutic Advances in Gastroenterology, 4, 433-442. http://dx.doi.org/10.1177/1756283X11398737

[6] Schapiro, M., Benjamin, S., Blackburn, G., et al. (1987) Obesity and the Gastric Balloon: A Comprehensive Workshop. Tarpon Springs, Florida, March 19-21, 1987. Gastrointestinal Endoscopy, 33, 323-327. http://dx.doi.org/10.1016/S0016-5107(87)71611-3

[7] Espinet-Coll, E., Nebreda-Durán, J., Gómez-Valero, J., et al. (2013) Current Endoscopic Techniques in the Treatment of Obesity. Revista Española de Enfermedades Digestivas, 104, 72-87. http://dx.doi.org/10.4321/S1130-01082012000200006

[8] Mion, F., Napoleon, B., Roman, S., et al. (2005) Effects of Intragastric Balloon on Gastric Emptying and Plasma Ghrelin Levels in Non-Morbid Obese Patients. Obesity Surgery, 15, 510-516. http://dx.doi.org/10.1381/0960892053723411

[9] Genco, A., Bruni, T., Doldi, S.B., et al. (2005) BioEnterics Intragastric Balloon: The Italian Experience with 2515 Patients. Obesity Surgery, 15, 1161-1164. http://dx.doi.org/10.1381/0960892055002202

[10] Dumonceau, J.M. (2008) Evidence-Based Review of the Bioenterics Intragastric Balloon for Weight Loss. Obesity Surgery, 18, 1611-1617. http://dx.doi.org/10.1007/s11695-008-9593-9

[11] Escudero-Sanchís, A., Catalán Serra, I., Gonzalvo Sorribes, J., Bixquert Jiménez, M., Navarro López, L., Herrera García, L., Durbán Serrano, L. and Monforte Albalat, A. (2008) Efectividad, seguridad y tolerancia del balón intragástrico asociado a una dieta hipocalórica para la reducción de peso en pacientes obesos. Revista Española de Enfermedades Digestivas, 100, 349-354. http://dx.doi.org/10.4321/S1130-01082008000600007

[12] Imaz, I., Martínez-Cervell, C., García-Álvarez, E., Sendra-Gutiérrez, J. and González-Enríquez, J. (2008) Safety and Effectiveness of the Intragastric Balloon for Obesity. A Meta-Analysis. Obesity Surgery, 18, 841-846. http://dx.doi.org/10.1007/s11695-007-9331-8

[13] Dastis, S., François, E., Deviere, J., Hittelet, A., Mehdi, A., Barea, M. and Dumonceau, J. (2009) Intragastric Balloon for Weight Loss: Results in 100 Individuals Followed for at Least 2.5 Years. Endoscopy, 41, 575-580. http://dx.doi.org/10.1055/s-0029-1214826

[14] Mathus-Vliegen, E.M. and Tytgat, G.N. (2005) Intragastric Balloon for Treatment-Resistant Obesity: Safety, Tolerance, and Efficacy of 1-Year Balloon Treatment Followed by a 1-Year Balloon-Free Follow-Up. Gastrointestinal Endoscopy, 61, 19-27. http://dx.doi.org/10.1016/S0016-5107(04)02406-X

[15] Badran, M. and Laher, I. (2011) Obesity in Arabic-Speaking Countries. Journal of Obesity, 2011, Article ID: 686430, 9 p. http://dx.doi.org/10.1155/2011/686430

[16] Salazar-Martinez, E., Allen, B., Fernandez-Ortega, C., Torres-Mejia, G., Galal, O. and Lazcano-Ponce, E. (2006) Overweight and Obesity Status among Adolescents from Mexico and Egypt. Archives of Medical Research, 37, 535542. http://dx.doi.org/10.1016/j.arcmed.2005.10.014

[17] ElGeidie, A. and ElHak, N.G. (2013) Laparoscopic Gastric Plication in Obese Egyptian Patients: Technique and Initial Short-Term Outcome. Surgery: Current Research, 3, 5.

http://omicsonline.org/laparoscopic-gastric-plication-in-obese-egyptian-patients-2161-1076-3-151.php?aid=21352

[18] Samy, M., Khairy, S., Ibrahim, S., Matter, M. and Hassan, H. (2012) Management of Overweight and Obesity in Egyptian School Children-An Intervention Study. Journal of American Science, 8. http://www.jofamericanscience.org/journals/amsci/am0811/089_12222am0811_595_603.pdf

[19] Dąbrowiecki, S., Szczęsny, W., Popławski, C. and Sosnowski, D. (2011) Intragastric Balloon (BIB System) in the Treatment of Obesity and Preparation of Patients for Surgery-Own Experience and Literature Review. Polish Journal of Surgery, 83, 181-187. http://dx.doi.org/10.2478/v10035-011-0028-2

[20] Nieben, O.G. and Harboe, H. (1982) Intragastric Balloon as an Artificial Bezoar for Treatment of Obesity. The Lancet, 
319, 198-199. http://dx.doi.org/10.1016/S0140-6736(82)90762-0

[21] Peker, Y., Durak, E. and Özgürbüz, U. (2010) Intragastric Balloon Treatment for Obesity: Prospective Single-Center Study Findings. Obesity Facts, 3, 105-108. http://dx.doi.org/10.1159/000295624

[22] Milone, M., Maietta, P., Bianco, P., Pisapia, A., Gaudioso, A., Goretti, G., Milone, F. and Musella, M. (2014) An Early Onset of Acute Renal Failure in a Young Woman with Obesity and Infertility Who Underwent Gastric Balloon Positioning. A Case Report. Il Giornale di Chirurgia, 35, 73-74.

[23] Alfredo, G., Roberta, M., Massimiliano, C., Michele, L., Nicola, B. and Adriano, R. (2014) Long-Term Multiple Intragastric Balloon Treatment-A New Strategy to Treat Morbid Obese Patients Refusing Surgery: Prospective 6Year Follow-Up Study. Surgery for Obesity and Related Diseases, 10, 307-311. http://dx.doi.org/10.1016/j.soard.2013.10.013

[24] Folini, L., Veronelli, A., Benetti, A., Pozzato, C., Cappelletti, M., Masci, E., Micheletto, G. and Pontiroli, A.E. (2014) Liver Steatosis Evaluated through Chemical-Shift Magnetic Resonance Imaging Liver Enzymes in Morbid Obesity; Effect of Weight Loss Obtained with Intragastric Balloon Gastric Banding. Acta Diabetologica, 51, 361-368. http://dx.doi.org/10.1007/s00592-013-0516-4 
Scientific Research Publishing (SCIRP) is one of the largest Open Access journal publishers. It is currently publishing more than 200 open access, online, peer-reviewed journals covering a wide range of academic disciplines. SCIRP serves the worldwide academic communities and contributes to the progress and application of science with its publication.

Other selected journals from SCIRP are listed as below. Submit your manuscript to us via either submit@scirp.org or Online Submission Portal.
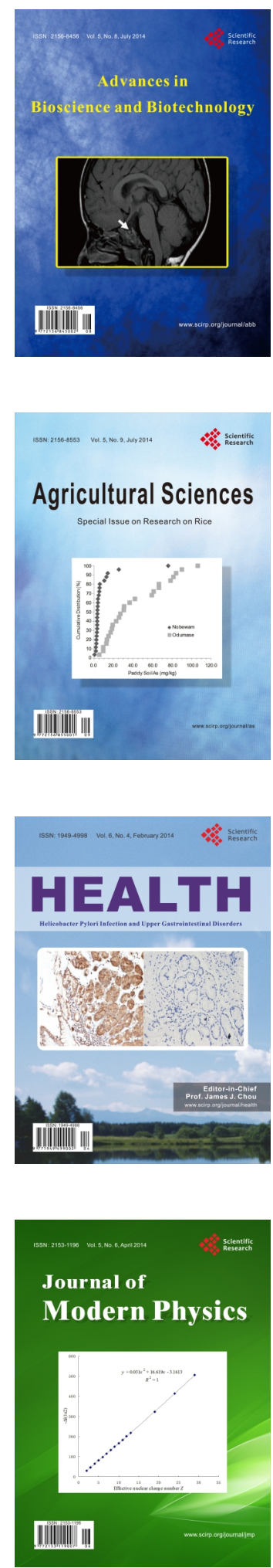
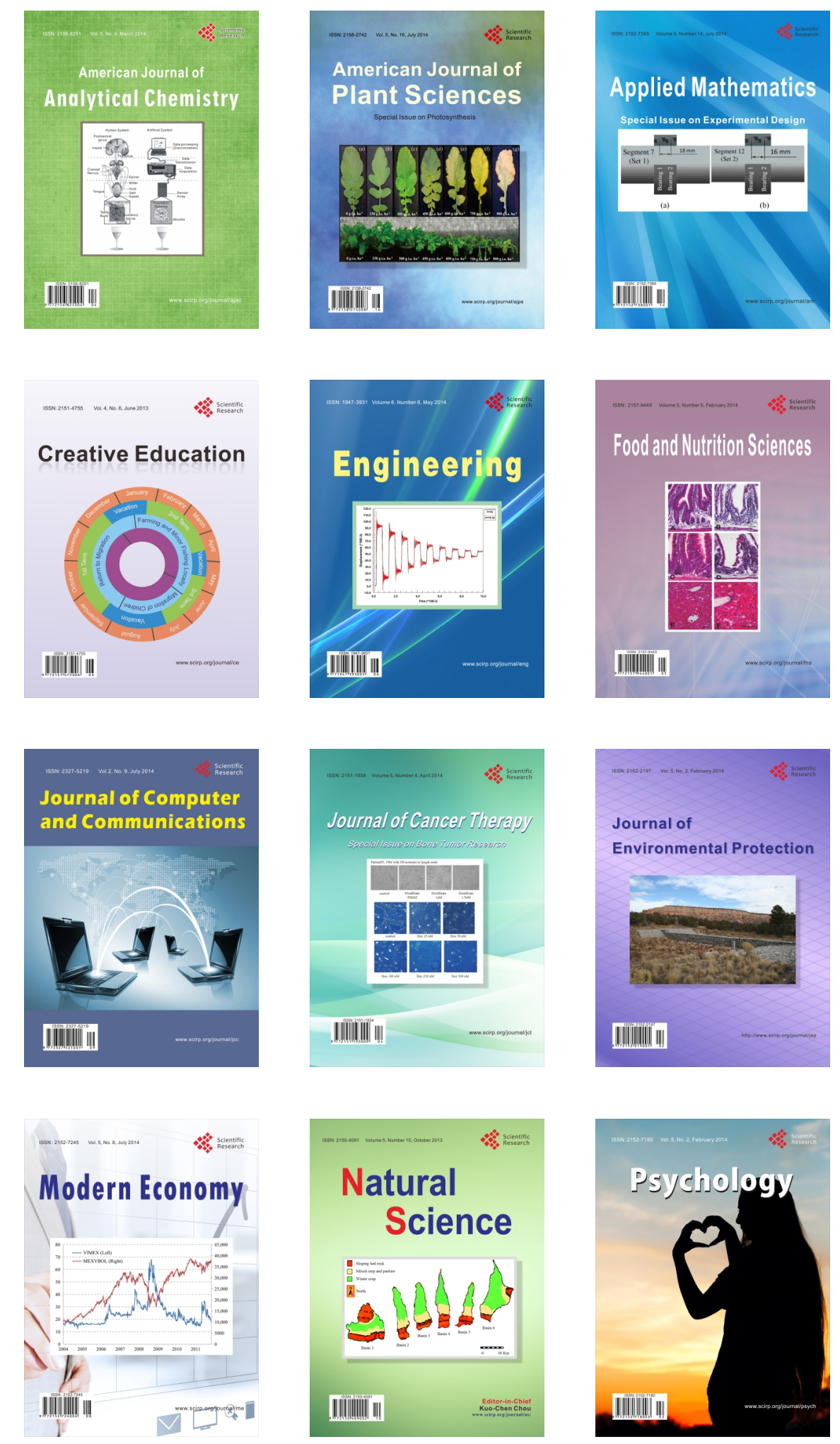